\title{
Experimental Research on Bone Biomechanics Characteristics of Vibration Intervention in Rats
}

\author{
Fuming Gu \\ Chengdu Sport University, Chengdu, P.R. China \\ fuminggu@foxmail.com
}

Keywords: Vibration training; bone tissue; biomechanics characteristics; rats; animal experiments.

\begin{abstract}
The purpose of this study was to explore the mechanical properties and functional adaptability of bone of vibration training in rats. Sixty rats were randomly assigned to four groups: control group, low frequency $(25 \mathrm{~Hz}, 3 \mathrm{~mm})$ vibration group, middle frequency $(35 \mathrm{~Hz}, 3 \mathrm{~mm})$ vibration group, and high frequency $(45 \mathrm{~Hz}, 3 \mathrm{~mm})$ vibration group, 15 rats/group. Vibration training was provided to each training group of rats on the Power Plate platform in vertical direction vibration. 5 days/week and 2 times/day for 8 weeks, 15 min/time. After training, the femurs and tibias were taken from rats and tests have been carried out on its mechanical properties. The conclusion showed that the effects on biomechanical properties of femurs and tibias of rats among different vibration frequencies varied widely. The suitable vibration frequency made the bone tissue possess some adaptability, namely the biomechanical characteristics were enhanced, otherwise the unsuitable vibration frequency made the bone tissue damage.
\end{abstract}

\section{Introduction}

Bone is an important component of human movement system, it is a living organ which has the structure and mechanical properties optimized to meet the requirements of force. Mechanical properties of bone significantly affected by categories (such as cortical and trabecular bone), the state of bone ( wet or dry), species, sex, age, external environmental factors, and the like, [1] therefore the bones cannot be ignored in sports training. In recent years, vibration training known as a new training methods in sports training is often used for muscle strength training, and this method has achieved some remarkable effects [2-4], but few studies have focused on the effects of vibration training on biomechanical properties (such as stress, strain, yield stress, load, elastic modulus etc.) of bone tissue and vibration training function adaptability of bone tissue. In this study, the author explored the effects of whole vibration training on bone biomechanical properties, this study has a comprehensive understanding of the effects of vibration training effects on biological tissue, and it has an improtant meaning on scientific training on both theroy and pracitce in avoiding damage caused by vibration training, as well as the further development of vibration training.

\section{Materials and Methods}

\subsection{Experimental Animals}

At the Experimental Animal Center under School of West China Medicine, Sichuan University, 60 healthy male SD rats with their weights ranging from $180 \mathrm{~g}$ to $210 \mathrm{~g}$.

\subsection{Feeding Methods and Grouping}

After one week's adaptive feeding, the rats are randomly divided into the following four groups: the rest control group $(\mathrm{C})$, the $25 \mathrm{~Hz}$ vibration training group $(\mathrm{L})$, the $35 \mathrm{~Hz}$ vibration training group $(\mathrm{M})$, and the $45-\mathrm{Hz}$ vibration training group $(\mathrm{H})$, with 15 rats per group. These rats are raised for 3 months in rack cages, with 5 rats per cage. The temperature for the movement and feeding environments is set between $18^{\circ} \mathrm{C}$ and $24^{\circ} \mathrm{C}$, and the relative humidity ranges from $45 \%$ to $55 \%$. They are exposed to natural light. In addition, all fed with standard pellet feed for rodents, and freely permitted to intake food and water. 


\subsection{Scheme for Vibration Training}

Vibration training is provided to each training group of rats on the Power Plate vibration training platform. When being trained, 15 rats of the same group are simultaneously placed on the vibrating platform. Each rat is respectively deployed to self-made organic glassware where such rat is restrained from standing up, and such rat's lower limbs are subject to vibrating stimulation under gravity-resistant conditions. Each day requires 2 vibration training sessions with each training session spanning $15 \mathrm{~min}$. The interval between the two vibration training sessions is $5 \mathrm{~min}$. The vertical amplitude of each group is $3 \mathrm{~mm}$. Such training is required 5 days each week with 2 days for rest, and lasts for 8 weeks.

\subsection{Animal Sampling}

Sampling is conducted within $24 \mathrm{~h}$ following the final vibration training for each group of rats. The $10 \%$ chloral hydrate solution $(3 \mathrm{~mL} / \mathrm{kg}$ ) is used to anesthetize such rats via intraperitoneal injection. The rats' right femur and tibia are sampled. Then, the extra peripheral tissues are cleaned away while leaving the wet femur and tibia. Using a vernier caliper (accuracy $0.02 \mathrm{~mm}$ ) the widest diameter and perpendicular to this in diameter of the proximal 1/3, middle $1 / 3,1 / 3$ distal (left, center, right three-point equidistant) of the femurs and tibias are measured, and then, according to statistical principles, calculated the average value of the diameter of the bone as its diameter, and cross-sectional area of the bone is calculated. The sample is wrapped in gauze, which has been soaked in a saline solution, and is immediately placed in a cryogenic vial pre-cooled with liquid nitrogen. After that, the vial is stored at $-80^{\circ} \mathrm{C}$ in a refrigerator for further testing.

\subsection{Mechanical Properties Testing}

At the Key Provincial Biomechanics Laboratory of Sichuan University, the femur and tibia for four-point bending testing are sandwiched in a test fixture and then placed on an electronic universal testing machine (AGIS-MS model) developed by Shimadzu. The load speed is $2 \mathrm{~mm}$. Thereafter, input relavant data and cross-sectional area of bone, the TRAPEZIUM 2 software on the electronic universal testing machine processes the data and outputs structural and mechanical parameters (including the maximal load and the energy absorbed at the maximal load) and mechanical parameters of materials (including modulus of elasticity, maximal stress,).

\subsection{Data analysis}

All data collected from this study were analyzed with SPSS 16.0 for Windows. One way ANOVA, LSD multiple comparison were used in this study. All significant level was set at $\mathrm{P}<0.05$ level, and extremely significant level at $\mathrm{p}<0.01$.

\section{Results and Analysis}

It is showed in table 1 . that (a) in low-frequency group $(25 \mathrm{~Hz})$, the elastic modulus and the maximum stress of femur significantly increased $(\mathrm{P}<0.05)$; the energy absorption at failure and maximum load are extremely significantly increased( $\mathrm{P}<0.01)$, while the maximum strain significantly reduced $(\mathrm{P}<0.05)$; (b) in middle-frequency group $(35 \mathrm{~Hz})$, energy absorption at failure, elastic modulus, and maximum stress significantly decreased $(\mathrm{P}<0.05)$, the maximum load and maximum strain extremely significant ly decreased ( $\mathrm{P}<0.01)$; (c) in high-frequency group $(45 \mathrm{~Hz})$, energy absorption, elastic modulus, maximum load and maximum stress significantly increased ( $\mathrm{P}$ $<0.01$ ), the maximum strain has no significant changes.

Compared with low-frequency, the energy absorption, elastic modulus, maximum load, and maximum stress has a very significant decrease $(\mathrm{P}<0.01)$ in middle-frequency group, the maximum strain was no significant difference ( $\mathrm{P}>0.05)$; energy absorption, elastic modulus, maximum load, and maximum stress of the femur are extremely significantly increased $(\mathrm{P}<0.01)$, the maximum strain was no significant difference $(\mathrm{P}>0.05)$.

The results show that (a) the vibration training in both low-frequency group $(25 \mathrm{~Hz})$ and high-frequency group $(45 \mathrm{~Hz})$ can improve biomechanical properties of the femur, and the middle-frequency group $(35 \mathrm{~Hz})$ will reduce the mechanical properties of rat femur. It may be due to the vibration frequency of $35 \mathrm{~Hz}$ is equal to or very close to the natural frequency of the femur (the 
natural frequency of rat's organs are missing in the literature), and it cause femur resonance phenomenon, make rats as affected by the forced oscillation overload, and beyond permissible load limit, and then result in the femur was hurt or cause tissue damage or dysfunction pathological bone absorption, so that the biomechanical properties of femur of $35 \mathrm{~Hz}$ training group significantly dropped.

According to the vibration theory, the acceleration amplitude of simple harmonic motion is proportional to the square of the vibration frequency. During vibration training, the biological tissue of trained animal performs forced vibration, so the higher the vibration frequency, the greater the load applied to the biological tissues, and is proportional to the square of the vibration frequency. Therefore, the load of $45 \mathrm{~Hz}$ vibration applied to the femur is larger than that of $25 \mathrm{~Hz}$ one. Based on the function adopatability of bone, the external force applied to the bone tissue can produce strain. When the bone tissue feel the changes around the surrounding condition, bone tissue growth will continue to carry out, strengthen or re-sorption in order to accommodate the needs of its mechanical functions. So the high-frequency group $(45 \mathrm{~Hz})$ femur performance parameters have very significantly increased $(\mathrm{P}<0.01)$.

From Table 2 it indicated that the biomechanical parameters of tibia in rats have the similar characteristics to the femur.

Table 1. Biomechanics parameter of femur of rats among different vibration frequencies $\quad(n=15)$

\begin{tabular}{|c|c|c|c|c|}
\hline Parameters & Control & Low & Middle & High \\
\hline $\begin{array}{c}\text { Energy } \\
\text { absoption(mJ) }\end{array}$ & $63.48 \pm 4.48$ & $68.82 \pm 5.17^{* *}$ & $59.45 \pm 4.08 * \boldsymbol{\Delta} \boldsymbol{\Delta}$ & $74.59 \pm 5.73 * * \Delta \Delta$ \\
\hline $\begin{array}{l}\text { Modulus of } \\
\text { elasticity(MPa) }\end{array}$ & $6456.74 \pm 523.29$ & $6896.34 \pm 516.63 *$ & $6014.64 \pm 524.30 * \boldsymbol{\Lambda} \Delta$ & $7639.31 \pm 617.37^{* *} \boldsymbol{\Delta} \Delta$ \\
\hline $\begin{array}{l}\text { Maximal } \\
\operatorname{load}(\mathrm{N})\end{array}$ & $106.34 \pm 8.35$ & $116.95 \pm 9.35 * *$ & $94.78 \pm 9.19 * * \boldsymbol{\Lambda} \Delta$ & $135.32 \pm 11.61^{* *} \boldsymbol{\Delta} \boldsymbol{\Delta}$ \\
\hline $\begin{array}{c}\text { Maximal } \\
\text { stress(MPa) }\end{array}$ & $39.09 \pm 4.02$ & $42.37 \pm 3.86^{*}$ & $35.46 \pm 3.85 * \boldsymbol{\Delta} \boldsymbol{\Delta}$ & $47.18 \pm 3.95^{* *} \boldsymbol{\Delta} \boldsymbol{\Delta}$ \\
\hline $\begin{array}{c}\text { Maximal strain } \\
(\%)\end{array}$ & $1.32 \pm 0.12$ & $1.21 \pm 0.13 *$ & $1.17 \pm 0.11 * *$ & $1.23 \pm 0.16$ \\
\hline
\end{tabular}

Note: Vibration intervention groups compared with control group, ${ }^{*} \mathrm{P}<0.05,{ }^{* *}: \mathrm{P}<0.01$.

Middle, high frequency groups compared with low frequency group, $\mathbf{\Lambda}: \mathrm{P}<0.05, \boldsymbol{\Delta} \mathbf{\Delta}: \mathrm{P}<0.01$.

Table 2. Biomechanics parameters of tibia of rats among different vibration frequencies $(\mathrm{n}=15)$

\begin{tabular}{|c|c|c|c|c|}
\hline Parameter & Control & Low & Medien & High \\
\hline $\begin{array}{c}\text { Energy } \\
\text { absoption(mJ) }\end{array}$ & $55.23 \pm 4.49$ & $58.53 \pm 4.61$ & $53.13 \pm 4.81 \boldsymbol{\Delta} \boldsymbol{\Delta}$ & $62.96 \pm 4.32 * * \boldsymbol{\Delta}$ \\
\hline $\begin{array}{l}\text { Modulus of } \\
\text { elasticity(MPa) }\end{array}$ & $6549.49 \pm 431.22$ & 7032.84ะ658.96* & $6296.95 \pm 506.75 \Delta \boldsymbol{\Delta}$ & $7464.88 \pm 517.09 * *$ \\
\hline $\begin{array}{c}\text { Maximal } \\
\operatorname{load}(\mathrm{N})\end{array}$ & $69.40 \pm 4.46$ & $73.29 \pm 5.71 *$ & $65.21 \pm 5.31 * \Delta \Delta$ & $77.93 \pm 6.19 * * \boldsymbol{\Delta}$ \\
\hline $\begin{array}{c}\text { Maximal } \\
\text { stress(MPa) }\end{array}$ & $39.96 \pm 4.51$ & $43.73 \pm 4.15 *$ & $38.51 \pm 4.09 \boldsymbol{\Delta} \boldsymbol{\Delta}$ & $47.61 \pm 4.43^{* *} \boldsymbol{\Delta}$ \\
\hline $\begin{array}{l}\text { Maximal } \\
\text { strain(\%) }\end{array}$ & $1.20 \pm 0.14$ & $1.13 \pm 0.11$ & $0.93 \pm 0.13^{* *} \boldsymbol{\Delta} \boldsymbol{\Delta}$ & $1.08 \pm 0.12^{*}$ \\
\hline
\end{tabular}

Note: Vibration intervention groups compared with control group, ${ }^{*}: \mathrm{P}<0.05,{ }^{* *}: \mathrm{P}<0.01$.

Middle, high frequency groups compared with low frequency group, $\boldsymbol{\Delta}: \mathrm{P}<0.05, \boldsymbol{\Delta} \mathbf{\Delta}: \mathrm{P}<0.01$. 


\section{Discussion}

Heredity, hormone levels, loads acting on the skeleton and other factors control the internal structure of the bone, the external structure and biomechanical properties. In 1892 in his famous "law of bone tranformation", German physician Wolff pointed out that each change in bone function is in accordance with the laws of mathematics, in a determined way to change its internal structure and external morphology. Bone is an organ of life, bone growth, change in shape, and re-sorption are associated with stress, and stress plays a regulatory role. Previous experiments proved that lower stress or higher stress will cause excessive bone loss or damage [6-8], so there is a best fit of bone to stress relationship.

The theory of functional adaptation of bone to bone theory seen as a control system with a feedback mechanism. Under normal circumstances, there is a physiological balance between mechanical stress suffered bone and bone tissue, that is, under certain stress conditions, bone resorption are mutually strengthening and balance, strengthen bone tissue caused by increased stress, stress the phenomenon is caused by the reduced resorption of bone tissue. Pauwels (1973) pointed out that when the bone tissue in optimal stress worth, steady changes in bone tissue is balanced. Within the upper and lower allowable stress, if the stress value is greater than the actual optimal stress value, osteoarthritis dominant, whereas when the actual stress values lower than the optimal stress value, resorption predominates. If the actual stress stress values higher than the maximum allowed, then the bone will be destroyed or pathological resorption of the damage, if the actual value is below the permissible limit stress stress value, resorption will stop. That stress is inadequate or excessive stress will cause the bone tissue atrophy or damage occurs.

From the results in this study, it indicated that there were significant diofferences in the bone biomechanical characteristics in rats among the different vibration frequencies. $25 \mathrm{~Hz}$ and $45 \mathrm{~Hz}$ vibration training can make a good adaptation of bone tissue, enhance its functions; but $35 \mathrm{~Hz}$ vibration training, Its frequencies is closer to or equal to the natural frequency of bone tissue, and then caused the bone tissue damage. The bone tissue after suffering an unsuitable stress, its biomechanical properties of strength or rigidity, or other biomechanical indicators will decreased, and the appropriate level of stress on bone tissue showed some adaptabilities, and the biomechanical feature was enhanced. Therefore, training in the application of vibration, the option of vibration frequency should be noticed by athletic training staff or medical supervisors.

\section{Conclusions}

In this vibration training experiment, the biomechanical properties of the femur and tibia of rats are affected to some extent. The effects of different vibration frequencies on the biomechanical properties of femur and tibia in rats were obvious difference. Suitable vibration frequency (stress) on bone tissue made it possess some adaptability, and its biomechanical characteristics were enhanced, inappropriate (excessive stress) vibration frequency will made bone damage. In order to achieve the desired effect of vibration training, the vibration frequency is selected to avoid the area to be close to the natural frequency of its training site system in the application of vibration training.

\section{Acknowledgements}

This study was supported by the Sports Medicine key laboratory of General Administration of Sport of China/Sports Medicine key laboratory of Sichuan province Foundation (No:2014CTYY007) and National Natural Science Foundation of China (No: 11272068). 


\section{References}

[1] Verschueren SM, Bogaerts A, Delecluse C, Claessens AL, Haentjens P, Vanderschueren $\mathrm{D}$, Boonen S.The effects of whole-body vibration training and vitamin $\mathrm{D}$ supplementation on muscle strength, muscle mass, and bone density in institutionalized elderly women: a 6-month randomized, controlled trial.Journal of Bone and Mineral Research : the Official Journal of the American Society for Bone and Mineral Research, 2011, 26(1):42-49

[2] Osawa Y, Oguma Y, Onishi S.Effects of whole-body vibration training on bone-free lean body mass and muscle strength in young adults. Journal of Sports Science \& Medicine, 2011, 10(1):97-104

[3] B. Humphries, A. Fenning. A preliminary study on whole-body vibration and resistance training on bone remodeling and exercise metabolism in young women, Journal of Science and Medicine in Sport, January 2010, 12(2), P117

[4] Giorgos Paradisis, Elias Zacharogiannis. Effects of whole-body vibration training on sprint running kinematics and explosive strength performance [J]. Journal of Sports Science and Medicine, 2007, 6(1): 44-49.

[5] Gu Fuming. Effect of Vibration Training on Biomechanical properties of Rat Gastrocnemius [J]. Journal of Chengdu Sport University, 2014, 40 (7):63-66.

[6] Michael Fredericson, etc., Tibia Stress Reaction in Runners Correlation of clinical Symptoms and Scintig-raphy with a New Maynetic Resonance Imaging Grading System [J]. The American J. of Sport Medicine, 1995, 23(1): 164-171.

[7] Hulkko A, Qrava S. Stress Fracture in Athletes [J]. Int. J Sports Med. 1987, 8:221-226.

[8] Tankisheva E., Bogaerts A., Boonen S., Delecluse, C., Jansen P., Verschueren S. Effects of a 6-month local vibration training on bone density, muscle strength, muscle mass and physical performance in postmenopausal women. Journal of Strength \& Conditioning Research: May 16, 2015 